\title{
Split-Bolus Multidetector-Row Computed Tomography Technique for Characterization of Focal Liver Lesions in Oncologic Patients
}

\author{
Michele Scialpi, ${ }^{1,}$ Luisa Pierotti, ${ }^{1}$ Sabrina Gravante, ${ }^{1}$ Alberto Rebonato, ${ }^{1}$ Irene Piscioli, ${ }^{2}$ Alfredo \\ D'Andrea, ${ }^{3}$ Raffaele Schiavone, ${ }^{4}$ and Barbara Palumbo ${ }^{5}$ \\ ${ }^{1}$ Department of Surgical and Biomedical Sciences, Division of Radiology 2, Perugia University, S. Maria Della Misericordia Hospital, Perugia, Italy \\ ${ }^{2}$ Department of Radiology, Budrio Hospital, Azienda USL Bologna, Budrio, Italy \\ ${ }^{3}$ Division of Radiology, San Giuseppe Moscati Hospital, Aversa, Italy \\ ${ }^{4}$ Division of Radiology, Meyer Pediatric Hospital, Florence, Italy \\ ${ }^{5}$ Department of Surgical and Biomedical Sciences, Division of Nuclear Medicine, Perugia University, S. Maria Della Misericordia Hospital, Perugia, Italy \\ "Corresponding author: Michele Scialpi, Department of Surgical and Biomedical Sciences, Division of Radiology 2, Perugia University, S. Maria Della Misericordia Hospital, P. O. \\ Box: 06156, Perugia, Italy. Tel: +75-5783507, Fax: +75-5783488, E-mail: michelescialpi@libero.it; michelescialpi1@gmail.com
}

Received 2014 May 13; Revised 2014 July 28; Accepted 2014 September 04.

\begin{abstract}
Background: In oncologic patients, the liver is the most common target for metastases. An accurate detection and characterization of focal liver lesions in patients with known primary extrahepatic malignancy are essential to define management and prognosis. Objectives: To assess the diagnostic accuracy of the split-bolus multidetector-row computed tomography (MDCT) protocol in the characterization of focal liver lesions in oncologic patients.

Patients and Methods: We retrospectively analyzed the follow-up split-bolus 64-detector row CT protocol in 36 oncologic patients to characterize focal liver lesions. The split-bolus MDCT protocol by intravenous injection of two boluses of contrast medium combines the hepatic arterial phase (HAP) and hepatic enhancement during the portal venous phase (PVP) in a single-pass.

Results: The split-bolus MDCT protocol detected 208 lesions and characterized $186(89.4 \%)$ of them: typical hemangiomas $(n=9)$, atypical hemangiomas $(n=3)$, cysts $(n=78)$, hypovascular $(n=93)$ and hypervascular $(n=3)$ metastases. Twenty two $(10.6 \%)$ hypodense lesions were categorized as indeterminate $(\leq 5 \mathrm{~mm})$. The mean radiation dose was $24.5 \pm 6.5$ millisieverts $(\mathrm{mSv})$.

Conclusion: The designed split-bolus MDCT technique can be proposed alternatively to triphasic MDCT and in a single-pass to PVP in the initial staging and in the follow-up respectively in oncologic patients.
\end{abstract}

Keywords: Helical Computed Tomography, Liver, Multidetector-Row CT, Neoplasm, Oncology, Split-Bolus Technique, Triphasic Technique

\section{Background}

Detection and characterization of focal liver lesions in patients with known primary extrahepatic are essential to define management and prognosis. Triphasic helical computed tomography (CT) - hepatic arterial phase (HAP), portal venous phase (PVP), and delayed phase (DP)- represents the standard of reference for the characterization of a wide range of focal liver lesions (1), but it results in a relevant radiation exposure.

Split-bolus multidetector-row CT (MDCT) is an innovative technique that, by splitting the intravenous (iv) contrast medium into two or three boluses and combining phase images in a single scan, can be used in cancer patients to reduce radiation dose (2-4).

\section{Objectives}

This study assessed the diagnostic efficacy of splitbolus MDCT technique in detecting and characterizing focal liver lesions in oncologic patients.

\section{Patients and Methods}

\subsection{Patients}

In this study, the MDCT scans of the chest-abdomenpelvis (CAP) of the previous two years were retrospectively analysed. Written informed consent for the split-bolus MDCT protocol was obtained from each patient and the research was performed according to the world medical association declaration of Helsinki. Thirty-six oncologic patients (19 males, 17 females; 42 - 80 years of age, mean age 63.3 years, weight $56-77 \mathrm{~kg}$, mean weight $68 \mathrm{~kg}$ ) underwent 
split bolus MDCT scanning $(n=36)$ of the CAP as a part of their follow-up care. No patient had cardiovascular insufficiency or liver cirrhosis.

All patients had known extrahepatic primary malignant cancer histologically confirmed: colorectal cancer ( $\mathrm{n}$ $=10)$, lung cancer $(n=11)$, breast cancer $(n=5)$, pancreatic cancer $(n=3)$, gastric cancer $(n=6)$, and melanoma $(n=1)$.

\subsection{Split-Bolus Multidetector-Row Computed Tomography Pro-} tocol

All patients were scanned with a 64-detector row scanner (Philips Healthcare, Best, The Netherlands). Our protocol consisted of unenhanced low-milliampere scans of the upper abdomen and a single scan of the CAP, after an iv injection of the of a maximum of $150 \mathrm{~mL}$ of contrast medium, Iopamiro $370 \mathrm{mgI} / \mathrm{mL}$ (Bracco, Milano, Italy) and Iopromide Ultravist 370 mgI/mL (Schering AG, Berlin, Germany), splitted by an automatic power injector (Medrad Stellant CT, Indianola, PA, USA) into two boli (Figure 1).

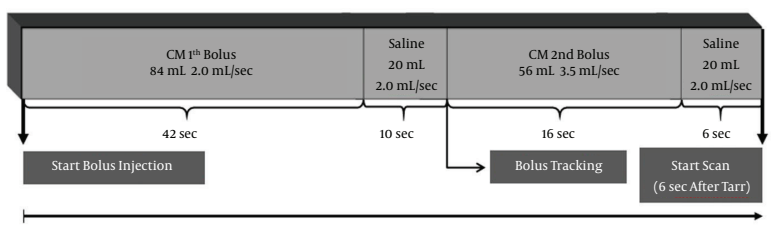

Figure 1. Schematic view of split-bolus 64-detector row CT technique of the chest and abdomen in a $70 \mathrm{Kg}$ patient. At start of bolus injection (or time zero), first bolus of $\mathrm{CM}(84 \mathrm{~mL}$ at $2.0 \mathrm{~mL} / \mathrm{sec})$, followed by $20 \mathrm{~mL}$ of saline at the same flow rate is injected (hepatic enhancement during the PVP); second bolus of $\mathrm{CM}(56 \mathrm{~mL}$ at 3.5 $\mathrm{mL} / \mathrm{sec}$, followed by $20 \mathrm{~mL}$ of saline at the same flow rate (HAP). Approximately at the end of the second bolus injection of CM, the scan started cranio-caudally after a delay of at least 6 seconds from the arrival of the CM in the aorta. An acquisition from the pulmonary apex to the pubic symphysis was performed resulting in a simultaneous contrast enhancement of the arterial and venous systems. CM: contrast medium. PVP: portal venous phase. HAP: hepatic arterial phase. *Arrival time of contrast medium in the aorta (Tarr).

Amount of contrast medium, duration of injection, and times were established on the basis of the literature data (5-7) and broad clinical experience.

In our patients who weighed $56-77 \mathrm{Kg}$, we obtained an adequate hepatic enhancement during the PVP by using a first bolus of contrast medium $(1.2 \mathrm{~mL} / \mathrm{kg})$ at a flow rate of 1.5-2 mL/sec. The adequate liver enhanncement during PVP had been determined based on an increase, after contrast medium administration, of more than 50 Hounsfield units (HU) when compared to unenhanced CT scans of the liver $(8,9)$. The HAP occurs at about 35 seconds after the start of iv injection of a second bolus of contrast medium ( 0.8 $\mathrm{mL} / \mathrm{kg}$ ) at 3-3,5 mL/sec.

Using the scout film, a scan range from the pulmonary apex to the pubic symphysis was determined. Then a circular region of interest (ROI) of the bolus-tracking technique (raising the threshold value to $500 \mathrm{HU}$ ) was placed into the descending aorta. Near the end of the second bolus injection of contrast medium, the scan started craniocaudally after a delay of at least 6 seconds from the arrival of the contrast medium in the aorta. The inherent 6 second delay in the bolus-tracking technique is necessary to move the scan tabulation to the start of the scan and to give breath-hold instructions to the patient.

A single contrast-enhanced acquisition was obtained, resulting in a simultaneous contrast enhancement of the arterial and venous systems. To increase the diagnostic accuracy of split-bolus MDCT for lesion characterization, a delayed phase DP at 5 minutes of the upper abdomen was performed. For the split-bolus MDCT protocol, the following acquisition parameters were used: slice thickness 2.5 $\mathrm{mm}$; gantry rotation speed 0.75 seconds; reconstruction index 1.25; pitch 0,935:1; and $120 \mathrm{kVp}$. The tube current was set to the automatic milliampere setting on the basis of the patient's weight. MDCT examinations were completed with sagittal and coronal multiplanar reconstructions (MPRs).

\subsection{Images Analysis}

Images were transferred to an external workstation and stored in a picture archiving and communication system (PACS) (RIS/PACS, IMPAX, Agfa healthcare, Mortsel, Belgium). All CT images were independently and in consensus reviewed by two radiologists (M.S. and A.D.A. with 25 and 15 years of experience in body CT, respectively). Any discrepancies concerning the diagnosis of liver lesions in terms of detection and characterization were resolved by consensus.

Attenuation of the aorta, main portal vein, and right lobe of the liver by a circular ROI were measured at combined HAP/PVP split-bolus scans. The appearance of each lesion at split-bolus MDCT was described on the basis of the attenuation and homogeneity of the lesion in comparison with the aorta according to the typical features of triphasic $\operatorname{MDCT}(10)$.

After describing the state of each lesion, the pattern of enhancement over time of each one was described as a two part pattern name that incorporated the appearance of the lesion in the combined phase (HAP/hepatic enhancement during PVP) and in the DP of the split-bolus protocol (e.g. hypo-(hypo-).

For the characterization of all focal liver lesions detected by split-bolus MDCT, the features were considered in terms of the number of lesions unchanged in size during follow-up on the triphasic CT (reference standard) and/or magnetic resonance imaging (MRI) and/or ultrasound at initial evaluation, as well as the appearance of each lesion at split-bolus. The findings indicated that the enhanc- 
ing pattern of focal liver lesions at split-bolus MDCT were similar to those recognized in the triphasic CT evaluation, which has also been reported in the literature (3). Furthermore, we even considered, as a reference standard, other diagnostic methods such as MRI and/or ultrasound, during a follow-up period of at least six months.

\section{Results}

The mean attenuation values of the aorta, the main portal vein, and liver parenchyma were $350.6 \pm 44.7 \mathrm{HU}$, $198.3 \pm 36.8 \mathrm{HU}, 112.4 \pm 14.5 \mathrm{HU}$, respectively. These values were not significantly different from those of the standard MDCT triphasic protocol at HAP and PVP reported in the literature $(3,5$ - 8).

On 208 focal liver lesions, split-bolus MDCT protocol characterized 186 (89.4\%) benign and malignant lesions: typical hemangiomas $(n=9)$, atypical hemangiomas $(n=$ $3)$, cysts $(n=78)$, hypovascular $(n=93)$ and hypervascular $(\mathrm{n}=3)$ metastases. Twenty two $(10.6 \%)$ hypodense lesions were categorized as indeterminate $(\leq 5 \mathrm{~mm})$.

The follow-up split-bolus MDCT protocol demonstrated similar results in the detection and characterization of focal liver lesions with respect to the triphasic protocol according to our experience and as reported in the literature $(1,3)$ (Table 1 ).

Representative cases by split-bolus MDCT are shown in Figures 2 - 4.
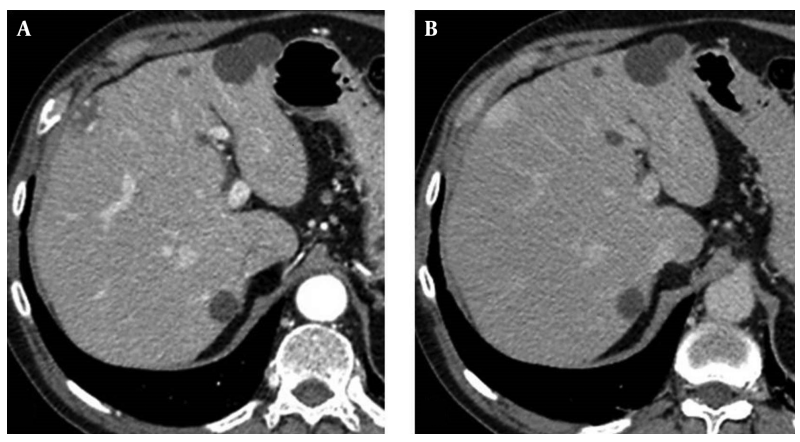

Figure 2. A, Split-bolus 64-detector row CT technique in a patient with lung cancer, multiple cysts, and subscapular typical hemangioma; B, The cysts appear hypodense and the hemangioma isodense to the hepatic vessels on the delayed phase at $5 \mathrm{~min}$ utes.

\section{Discussion}

In oncologic patients, the rationale for an appropriate use of the CT is to optimize and standardize protocols to reduce radiation dose and to ensure diagnostic efficacy.
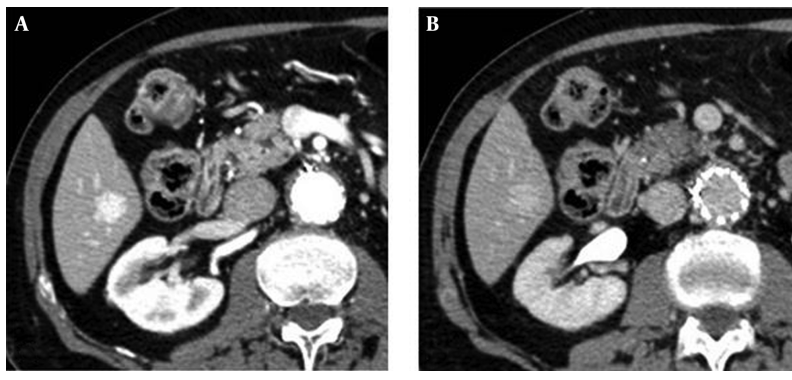

Figure 3. A, Split-bolus 64-detector row CT technique in a patient with colorectal cancer and rapid flow atypical hemangioma in the right lobe (segment VI); B, Lesion appears substantially hyperdense to liver parenchyma on the delayed phase at 5 minutes.
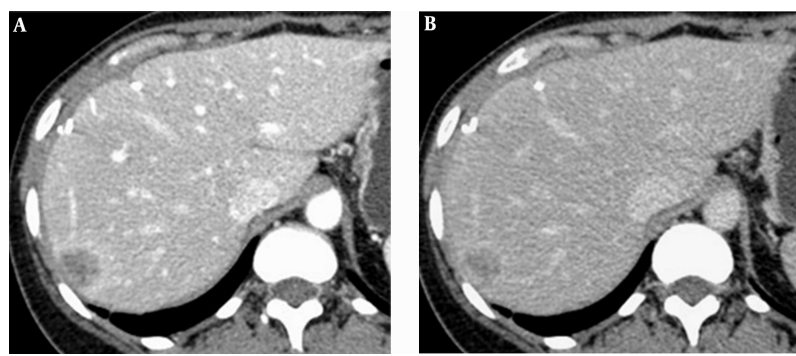

Figure 4. A, Split-bolus 64-detector row $\mathrm{CT}$ technique in a patient with colorectal cancer and hypodense metastasis in the right lobe of the liver; B, Lesion appears inhomogeneous hypodense to liver parenchyma on the delayed phase at 5 minutes.

In this study, we implemented an innovative splitbolus MDCT protocol that combined the HAP and hepatic enhancement during PVP in a single acquisition, allowing the identification of hypo-, hypervascular, and mixed focal liver lesions. A DP at 5 minutes of the upper abdomen further helped in the characterization of the lesions.

The split-bolus technique consists of splitting the iv contrast medium into two boluses and performing MDCT acquisition in a single-pass. The rationale is similar to that of the CT urography protocol $(4,11)$ with the same goal of reducing the radiation dose.

In our study, using a flow rate of $1.5-2 \mathrm{~mL} / \mathrm{sec}$ for the first bolus of contrast medium, an adequate attenuation in $\mathrm{HU}$ of the main portal vein and the liver parenchyma (more than a 50 HU increase of the liver enhancement during PVP, in comparison to unenhanced CT scan) was obtained $(8,9)$. The second bolus of $45-60 \mathrm{~mL}$ of contrast medium at 3 $3.5 \mathrm{~mL} / \mathrm{sec}$ ensured an adequate enhancement of the aorta during HAP.

The main goal of this innovative technique in oncologic patients, is to ensure a reproducible protocol and an imaging quality of diagnostic efficacy. Instead of obtaining two scans separately at the HAP and hepatic enhancement 
Table 1. Enhancement Patterns of Focal Liver Lesions by Triphasic and Split-Bolus Computed Tomography Techniques ${ }^{\mathrm{a}}$

\begin{tabular}{|c|c|c|c|c|c|}
\hline \multirow[t]{3}{*}{ Focal Liver Lesion } & \multicolumn{5}{|c|}{ Enhancement Patterns } \\
\hline & \multicolumn{3}{|c|}{ Triphasic Technique } & \multicolumn{2}{|c|}{ Split-Bolus Technique } \\
\hline & HAP & PVP & DP & HAP/PVP & DP \\
\hline Cysts & Нypo- & Hypo-(cyst) & Нypo- & Hypo-(cyst) & Нypo- \\
\hline \multirow[t]{4}{*}{ Typical hemangioma } & Нypo- & Нypo- & Нypo- & Hypo- & Нypo- \\
\hline & Нypo- & Нyро- & Hyper- & Нyро- & Hyper \\
\hline & A & A & A & A & A \\
\hline & Hyper- & A & A & Hyper- & A \\
\hline \multicolumn{6}{|l|}{ Atypical hemangioma (10) } \\
\hline 1a & Hyper- ${ }^{\text {b }}$ & Hyper-(no THAD) ${ }^{\mathrm{b}}$ & Iso & Hyper-(no THAD) ${ }^{\mathrm{b}}$ & Iso \\
\hline $1 \mathrm{~b}$ & Hyper- & Hyper-(THAD) & Iso & Hyper-(THAD) & Iso \\
\hline $2 a$ & Нypo- & Hypo-(homogeneous) & Iso & Hypo-(homogeneous) & Iso \\
\hline $2 \mathrm{~b}$ & Нypo- & Hypo-(inhomogeneous) ${ }^{c}$ & Iso & Hypo-(inhomogeneous) ${ }^{c}$ & Iso \\
\hline 3 & Нypo- & Hypo-(inhomogeneous) ${ }^{d}$ & Iso & Hypo-(inhomogeneous) ${ }^{d}$ & Iso \\
\hline \multirow[t]{5}{*}{ Metastases } & Нypo- & Нуро- & Нypo- & Нyро- & Нypo- \\
\hline & Hyper-(rim) & Нyро- & Нypo- & Hyper-(rim) & Нypo- \\
\hline & Нypo- & Нypo- & Hyper- & Нypo- & Hyper- \\
\hline & Hyper- & A & A & Hyper- & A \\
\hline & Mixed & Mixed & Mixed & Mixed & Mixed \\
\hline Indeterminate lesions $(\leq 5 \mathrm{~mm})$ & Нypo- & Нyро- & Нypo- & Нyро- & Нypo- \\
\hline
\end{tabular}

during PVP, as it occurs in bi- or triphasic CT techniques, it is possible to obtain a single combined phase scan. This results in reduction of the radiation dose, especially over the long-term and, moreover, in a decrease in the number of images to be analyzed and the amount of data stored on the PACS, in comparison to the triphasic CT technique.

The split-bolus MDCT technique by combined HAP and hepatic enhancement during PVP, in addition to 5 minutes DP, allowed an accurate characterization of focal liver lesions similar to those of a triphasic CT (3).

Our study has some limitations: the small number of the patients, and the retrospective study design. In oncologic patients, the designed technique can be proposed alternatively to bi- or triphasic MDCT and in a single-pass to $\mathrm{PVP}$ in the initial staging and in the follow-up respectively.

\section{Footnotes}

Authors' Contribution: Michele Scialpi, performed experiments, analyzed data, interpreted results of experiments, prepared figures, drafted the manuscript, conceived and designed the research, and approved the final version of the manuscript; Luisa Pierotti, Sabrina Gravante, Irene Piscioli, and Alberto Rebonato, performed ex- periments, analyzed data, interpreted results of experiments, prepared figures, drafted the manuscript, and edited and revised manuscript; Alfredo D'Andrea and Raffaele Schiavone, analyzed data, interpreted results of experiments and edited and revised the manuscript; Barbara Palumbo, conceived and designed the research, interpreted results of experiments, and approved the final version of manuscript. And all authors read and approved the final manuscript.

Financial Disclosure: The authors declare no financial interests or other conflicts of interest.

Funding/Support: The authors declare no funding support.

\section{References}

1. van Leeuwen MS, Noordzij J, Feldberg MA, Hennipman AH, Doornewaard H. Focal liver lesions: characterization with triphasic spiral CT. Radiology. 1996;201(2):327-36. doi: 10.1148/radiology.201.2.8888219. [PubMed: 8888219].

2. Brook OR, Gourtsoyianni S, Brook A, Siewert B, Kent T, Raptopoulos V. Split-bolus spectral multidetector CT of the pancreas: assessment of radiation dose and tumor conspicuity. Radiology. 2013;269(1):139-48. doi: 10.1148/radiol.13121409. [PubMed: 23674791]. 
3. Scialpi M, Palumbo B, Pierotti L, Gravante S, Piunno A, Rebonato A et al. Detection and characterization of focal liver lesions by splitbolus multidetector-row CT: diagnostic accuracy and radiation dose in oncologic patients. Anticancer Res. 2014;34(8):4335-44. [PubMed: 25075068].

4. Kekelidze M, Dwarkasing RS, Dijkshoorn ML, Sikorska K, Verhagen PC Krestin GP. Kidney and urinary tract imaging: triple-bolus multidetector CT urography as a one-stop shop-protocol design, opacification, and image quality analysis. Radiology. 2010;255(2):508-16. doi: 10.1148/radiol.09082074. [PubMed: 20160002].

5. Bae KT. Intravenous contrast medium administration and scan timing at CT: considerations and approaches. Radiology. 2010;256(1):3261. doi: 10.1148/radiol.10090908. [PubMed: 20574084].

6. Erturk SM, Ichikawa T, Sou H, Tsukamoto T, Motosugi U, Araki T. Effect of duration of contrast material injection on peak enhancement times and values of the aorta, main portal vein, and liver at dy namic MDCT with the dose of contrast medium tailored to patient weight. Clin Radiol. 2008;63(3):263-71. doi:10.1016/j.crad.2007.02.024. [PubMed: 18275866].

7. Ichikawa T, Erturk SM, Araki T. Multiphasic contrast-enhanced multidetector-row CT of liver: contrast-enhancement theory and practical scan protocol with a combination of fixed injection duration and patients' body-weight-tailored dose of contrast material.Eur
J Radiol. 2006;58(2):165-76. doi: 10.1016/j.ejrad.2005.11.037. [PubMed: 16417983].

8. Heiken JP, Brink JA, McClennan BL, Sagel SS, Crowe TM, Gaines MV. Dynamic incremental CT: effect of volume and concentration of contrast material and patient weight on hepatic enhancement. Radiology. 1995;195(2):353-7. doi: 10.1148/radiology.195.2.7724752. [PubMed: $7724752]$.

9. Yamashita Y, Komohara Y, Takahashi M, Uchida M, Hayabuchi N, Shimizu T, et al. Abdominal helical CT: evaluation of optimal doses of intravenous contrast material-a prospective randomized study. Radiology. 2000;216(3):718-23. doi: 10.1148/radiology.216.3.ro0se26718. [PubMed: 10966700].

10. Scialpi M, Volterrani L, Mazzei MA, Cappabianca S, Barberini F, et al. Small $(<$ or $=2 \mathrm{~cm}$ ) atypical hepatic haemangiomas in the noncirrhotic patient: pattern-based classification scheme for enhancement at triple-phase helical CT. Radiol Med. 2009;114(6):935-47. doi: 10.1007/s11547-009-0427-1. [PubMed: 19579014].

11. Portnoy O, Guranda L, Apter S, Eiss D, Amitai MM, Konen E. Optimization of 64-MDCT urography: effect of dual-phase imaging with furosemide on collecting system opacification and radiation dose. AJR Am J Roentgenol. 2011;197(5):W882-6. doi:10.2214/AJR.11.6965. [PubMed: 22021536]. 